\title{
A case study of developing ICT-supported pedagogy through a collegial practice transfer process
}

\section{Lakkala, Minna}

2015-12-01

Lakkala , M \& Ilomäki , L 2015 , ' A case study of developing ICT-supported pedagogy

through a collegial practice transfer process ' , Computers \& Education , vol. 90 , pp. 1-12 . https://doi.org/10.1016/j.c

http://hdl.handle.net/10138/297739

https://doi.org/10.1016/j.compedu.2015.09.001

cc_by_nc_nd

acceptedVersion

Downloaded from Helda, University of Helsinki institutional repository.

This is an electronic reprint of the original article.

This reprint may differ from the original in pagination and typographic detail.

Please cite the original version. 


\section{A case study of developing ICT-supported pedagogy through a collegial practice transfer process}

Minna Lakkala ${ }^{a^{*}}$ and Liisa Ilomäki ${ }^{\mathrm{b}}$

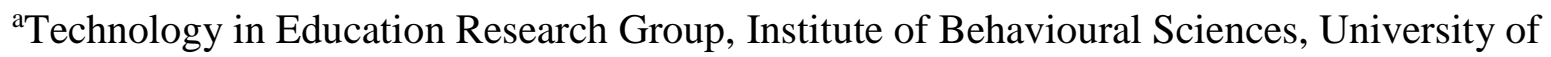
Helsinki, P.O. Box 9, 00014 University of Helsinki, Finland

Email: minna.lakkala@helsinki.fi

${ }^{\mathrm{b}}$ Technology in Education Research Group, Institute of Behavioural Sciences, University of Helsinki, P.O. Box 9, 00014 University of Helsinki, Finland

Email: liisa.ilomaki@ helsinki.fi

*Corresponding author.

Final published version:

Lakkala, M., \& Ilomäki, L. (2015). A case study of developing ICT-supported pedagogy through a collegial practice transfer process. Computers \& Education, 90, 1-12. doi:

http://dx.doi.org/10.1016/j.compedu.2015.09.001 


\title{
A case study of developing ICT-supported pedagogy through a collegial practice transfer process
}

\begin{abstract}
A collegial practice transfer process between more- and less-experienced teachers was examined in two cases that sought to encourage teachers to use information and communication technology (ICT) in a pedagogically meaningful way. Collegial practice transfer is aimed at offering new models for in-service teacher training. The process included guiding sessions, training materials presenting authentic pedagogical examples, and try-outs in the classroom. The success of practice transfer was examined through comparing the classroom practices of more- and less-experienced teachers applying the Pedagogical Infrastructure Framework, and through analyzing the tutored teachers' self-reported experiences in interviews. The process provided flexible support and gave self-confidence to the less-experienced teachers. Technology use was successful, but the tutored teachers designed less coherent tasks and weaker support for pupils' collaboration, knowledge construction and metacognition than their more-experienced colleagues. In tutoring, underlying educational ideologies and reasons should be explicated in addition to practical issues of classroom orchestration and technology use.
\end{abstract}

Keywords: cooperative/collaborative learning, elementary education, improving classroom teaching, pedagogical issues, teaching/learning strategies

\section{Highlights}

Collegial tutoring inside a school is a flexible ICT training method for teachers.

Tutoring encourage novice teachers to try new practices with ICT in teaching.

Support for cultivating pedagogical approaches is more critical than technology use.

Systematic procedures for the tutoring practice make it more effective.

\section{Introduction}

Schools and teachers still face major problems in implementing the new digital technology in teaching and learning, in spite of extensive efforts by educational administrations (e.g., EC, 2013; OECD, 2011). There are individual schools in which technology is used widely, and teachers who have updated their pedagogical practices, but the majority of schools and teachers have not adopted new ways of working (Jimoyiannis \& Komis, 2007; Orlando, 2009). Technology is still mainly used for supporting traditional teaching methods, such as information sharing, or doing simple exercises (OECD, 2010a; EC, 2013). Advanced pedagogical practices with the new technology do not spread by itself, technology is often implemented within existing educational structures, methods and curriculum, and technology does not work as a catalyst for educational reforms (Ilomäki, 2008).

Voogt, Fisser, Pareja Roblin, Tondeur and van Braak (2013) made a review about the new expertise that teachers need for adopting digital technologies in teaching. They concluded that each educational setting is an intertwined combination of content, pedagogy and the potential of technology; a teacher should master all these domains. Too often individual teachers are asked to make major changes in their teaching with new technology without proper and sufficient support. It is also a challenge to develop teachers' professional competence through conventional training, because new knowledge and practices are difficult to adopt when separated from the authentic teaching situations (Krumsvik, 2008). In typical ICT training programs for in-service teachers, technology, pedagogy, and subject domain content are studied separately, which does not provide 
teachers with competencies for integrating them in a successful way into their classroom practice (Hyo-Jeong \& Kim 2009). Karagiorgi and Charalambous (2006) concluded that the pressure to maintain the existing classroom environment and the existing culture is very strong. Wang (2006) and Zhou (2007) stated that one-time-only workshops and hands-on training are not effective in making teachers comfortable with using technology; rather, a follow-up program or mentoring is necessary after the initial training. Teachers would benefit from concrete examples about using ICT in teaching and support provided for them in situ in their everyday classroom situations (Putnam \& Borko, 2000; Condie, Munro, Seagraves, \& Kenesson, 2007).

In order to find new methods for in-service teachers' ICT training, a European-level project Fostering ICT Usages in Pedagogical Practices (FICTUP) was created to develop a practice transfer model where experienced teachers supported their less-experienced colleagues in implementing digital technologies in their teaching through authentic examples and guidance. The main aim was to disseminate pedagogical practices, which are based on experienced teachers' well-tried and cultivated practices, represent ambitious pedagogical approaches, and are closely linked to the pedagogical objectives of the school in question. In the present study, the practice transfer model was tested in two case studies in Finnish elementary schools.

\subsection{Teacher collaboration and sharing of expertise as means for developing ICT-supported pedagogy}

Fogarty and Pete (2010) listed features that are important for successful professional learning of in-service teachers: the development practices should, e.g., be job-embedded (everyday support in the workplace available), collegial (professional collaboration), interactive (active involvement and hands-on activities) and practical (connections and applicability in everyday work). In a national innovation project of Dutch teachers, Bakkenes, Vermunt, and Wubbels (2010) found that teacher learning and experiments in practice go hand in hand, and that informal learning did not bring as positive results as organized learning, especially reciprocal working with a peer or a collaborative project team. Jones and Vincent (2010) reported results from two projects where teachers were supervised by colleagues mentoring the use of Interactive White Boards (IWBs) in their teaching. The results from the projects indicated that the support from the peer mentor helped to reduce the teachers' fear of the technology and its unexpected consequences in the classroom.

Starkey (2010) sought to identify what were the barriers and enablers influencing the integration of digital technologies into teaching by digitally able newly-qualified teachers. According to the results, crucial influential factors in the school context included: school policies and structures which promoted and provided access to digital technologies, encouragement to new teachers in developing their sense of agency, and the support of a mentor with relevant pedagogical content expertise.

Collegial collaboration practices are not relevant only for supporting professional learning of individual teachers. When aiming at more profound and sustainable change in the quality of teaching through ICT, the teachers of the same school should share knowledge, experiences and best practices as well as create together new innovative pedagogical methods. Schools should create deliberate visions and strategies about using ICT as well as encourage the collaboration and engagement of the teaching staff in the development work (OECD, 2010b). The practice transfer process as applied in the present study is one effort to find effective ways to promote pedagogical development work and disseminate pedagogical ICT-related innovations inside a school.

\subsection{A framework for examining pedagogical practices in the classroom}

In the present study, the success and challenges of practice transfer are evaluated through examining how the participating more- and less-experienced teachers designed and conducted a 
pedagogical unit, including the usage of ICT, in their classrooms, complemented by their own reflections on the process. Because teachers' own descriptions or self-reflections often give an incomplete or too positive view of their pedagogical methods, we chose to examine authentic classroom practices with pupils, which would better reveal how the less-experienced teachers adapt and implement the practices introduced to them by the more-experienced teachers.

A teacher's task in technology-rich collaborative settings is both 1) to plan, structure, and orchestrate the learners' activity by establishing the underlying educational conditions for the collective effort (overall design), and, 2) to participate in the working process as a guide who provides adapted, situation-specific guidance to the learners (scaffolding) (Hogan \& Pressley, 1997; Lakkala, Muukkonen, \& Hakkarainen, 2005). In the present study, both the overall design and the scaffolding practices in the classroom were included in the analyses.

A starting point for investigating the classroom practices was a conceptualization, or a framework, used for examining the basic elements in the classroom implementations in a unifying way. In ambitious pedagogical practices, including the rich use of technology and complex, productive activities that rely on the students' active engagement and collaboration, the planning and orchestration of the educational setting requires taking an overarching perspective on the pedagogical set-up. The requirement to take the complexity of such learning settings into account in educational research has been stated by various researchers (e.g., Puntambekar, Stylianou, \& Goldstein, 2007; Scardamalia \& Bereiter, 2006). In the present study, we apply the Pedagogical Infrastructure Framework, which has been developed for describing the central elements in the teachers' pedagogical practices representing technology-enhanced, collaborative knowledge creation (Lakkala, Ilomäki, \& Kosonen, 2010). The idea for using infrastructure as a metaphor is adopted from studies emphasizing how the orchestration of collaborative learning is indirect, that is, setting up background conditions that mediate intended social and cultural practices but not prescribing the contents or tasks in detail (Bielaczyc, 2006; Jones, Dirckinck-Holmfeld, \& Lindström, 2006; Paavola, Lipponen, \& Hakkarainen, 2002).

The Pedagogical Infrastructure Framework is not normative in itself; it is meant to examine and evaluate the design features in any educational setting in a structured fashion, drawing attention to some critical elements. The basic components of the framework are the following:

- Technical structures: All arrangements related to using digital technologies in the setting: the type of tools, appropriateness of tools for the purpose, or guidance and promotion of digital competence of pupils.

- Social structures: Social nature of activities, such as social interaction and co-construction practices, explicit guidance and arrangements for advancing collaboration, or sharing of the process and outcomes.

- Epistemological structures: The nature of practices and tasks concerning working with knowledge and information; for instance, the usage of knowledge sources, participants' role while creating and sharing knowledge, or guidance for pupils about using and producing knowledge.

- Cognitive structures: Tasks, activities and guidance related to the promotion of pupils' cognitive engagement and metacognitive competence, such as providing models, templates, and conceptual tools, explicating goals and performance criteria, or organizing selfregulatory activities.

\subsection{Aims of the study}

The aim of the present study was to evaluate the success of the practice transfer process by examining the classroom practices of two less-experienced teachers, compared with those of the more-experienced teachers who tutored the less-experienced teachers in implemented specific learning activities. It is not possible to substantially improve teachers' professional practices only 
through short-term, one-time training or experimentation process. Therefore, we do not even expect the pedagogical infrastructure built by the less-experienced teachers to be as sophisticated as that of the more-experienced teachers. However, by evaluating the classroom implementations in detail, we expect to better understand major challenges that less-experienced teachers face when implementing ICT and collaboration activities in their classroom.

The research questions of the study are the following:

1. What can be concluded about the success of practice transfer from the similarities and differences in the classroom implementations between the less- and more-experienced teachers?

2. How do the tutored teachers describe the benefits of the practice transfer process?

3. What recommendations can be made based on the results for improving the practice transfer method and collegial tutoring in promoting pedagogically sophisticated use of ICT?

\section{Method}

The general methodological approach was a multiple case study method where two practice transfer processes between a more- and less-experienced teacher teaching with ICT were investigated. A mixed method strategy (Feilzer, 2009) was chosen for data collection and analysis because authentic settings are complex environments, and it is not possible to capture various elements of the phenomena through any single method. A variety of data sources were used: videotaped classroom lessons, interviews, and database contents; and qualitative and quantitative methods were combined in data analyses.

\subsection{Setting and Participants}

The case studies represented the Finnish contribution to the EU-supported FICTUP project (http://www.fictup-project.eu). There were one more-experienced and one less-experienced teacher in both case studies. The aim was to create guidelines for practice transfer to be applied locally in schools in order to disseminate good pedagogical practices with ICT. The practice transfer process consisted of the following elements (see FICTUP, 2010):

- Orientation materials (written scenarios and related videos) describing concrete pedagogical activities of the experienced teacher using ICT in the classroom: (FICTUP, 2013a; FICTUP, 2013b). Both experienced teachers had conducted similar working processes in their classrooms before; and the practices were also in line with the school-level strategies about the desirable pedagogical approaches with ICT.

- Discussion sessions between more- and less-experienced teachers where the moreexperienced teachers described their pedagogical practices, gave advice and recommendations as well as helped the less-experienced teachers plan their own pedagogical scenario.

- The less-experienced teachers implemented the plan in their own classroom and received advice from the more-experienced colleague between the lessons. The tutoring teachers also participated in some of the lessons.

- Finally, the teachers arranged a post-session where they evaluated the experiences and degree of success of the less-experienced teachers' implementation of the plan.

The investigated cases were selected for the project because the pedagogical development work in both schools was based on quite systematic school-level aims. In the schools, much effort has been invested, already for several years, in improving teachers' pedagogical practices and using ICT in an innovative way. The more-experienced teachers participating in the study shared the goals of their school and were willing to contribute to school-level development. The teachers were experienced in using ICT in teaching, they had participated in various development projects, and 
they were acknowledged teacher trainers on the municipal level. The more-experienced teachers chose the less-experienced teachers from among their colleagues at the same school.

In Case 1, the teachers carried out inquiry projects in biology where elementary school pupils studied phenomena related to courtyard plants. Their school has a strategy to increase inquiry-based practices in teaching. The theme of the project conducted by the more-experienced teacher (MET1) was 'Growth factors of courtyard plants'. The pupils were between nine and ten years of age. The theme in the project of the less-experienced teacher (LET1) was 'Life around the school', and the pupils were between 10 and 11 years of age. Various tools of a web-based collaboration system (Fronter) as well as an interactive whiteboard (IVB) were used for documenting and sharing the pupils' ideas and contributions. Fronter is a virtual environment which the local school administration had chosen for all its schools.

MET1 was a male teacher with 20 years of teaching experience, 19 of them at the school in question. He was 44 years old and had used ICT in teaching for 20 years, 24 years altogether. He was the teacher in charge of ICT issues at his school and an active developer concerning ICT in education outside the school, working as a teacher trainer and scriptwriter of educational materials. LET1 was a 29-years-old female teacher, who had been working as a teacher for four years, two years at the school in question. She had used ICT somewhat in her teaching since she started working as a teacher, altogether 13 years. She had used the web-based learning environment somewhat during the previous year but had never created a new virtual room there by herself. She had not used the IWB before.

In Case 2, the classroom project of both teachers focused on writing stories for the school journal on the Web. The school has an emphasis on supporting pupils' innovation skills and digital competence; writing the journal was planned to be a common practice, among other activities, for all pupils to support their digital competence. The pupils of the more-experienced teacher (MET2) were from 11 to 12 years of age; those of the less-experienced teacher (LET2) were from eight to nine years of age. About one third of the pupils in both classes had special education needs. The journal was published with the Magazine Factory program (http://mazinefactory.edu.fi), which is a free publishing application for schools that simulates professional publication practices. Besides that, word processing programs, digital cameras, and IVBs were used.

MET2 was a 52-year-old male teacher with 26 years of teaching experience, two of them at the school in question. He has used ICT for about 15 years in teaching, and about 17 years in all. He has belonged to an ICT expert teacher team in his city for several years, training other teachers to use ICT in teaching. LET2 was a 32-year-old male teacher who had started working at the school in the current school year. He had worked as a teacher for five years. He had used various ICT tools somewhat with his pupils throughout those five years (e.g. text processing, graphics, and IVBs) and for personal purposes for 15 years, but the Magazine Factory application was new to him.

\subsection{Data Collection}

The classroom lessons of the pedagogical units conducted by the four teachers were observed and videotaped by one or two researchers. The duration and scheduling of each pedagogical unit was as follows (one lesson was about 45 minutes):

- MET1 - Growth factors: $3+1$ lessons in the first week, $3+2$ lessons in the second week, and 1 lesson in the third week; 10 lessons and 3 weeks in all;

- LET1 - Life around the school: 3 lessons in the first week, $2+1$ lessons in the second week and 1 lesson in the third week; 7 lessons and 2.5 weeks in all;

- MET2 - Web journal: 2 lessons per week for five weeks, and 1 lesson in the last week; 11 lessons and 6 weeks in all;

- LET2 - Web journal: 1-2 lessons per week for six weeks; 8 lessons and 6 weeks in all. 
The teachers were briefly interviewed before and after each lesson or a series of consecutive lessons, asking a few questions about the lesson. An in-depth, final interview was carried out at the end of the process with the tutored teachers individually. The interviews addressed issues related to the strengths and weaknesses they had experienced of the practice transfer process in general and its various elements, such as the materials provided, tutoring, and the classroom implementation (the interview questions are available at FICTUP, 2010). We also collected all the documents, writings, and other outcomes produced by the teachers and the pupils in the web-based environments during the process.

\subsection{Data Analysis}

First, the overall actual, patterned process of each pedagogical unit - the structure and phases of the activity during the unit - was reconstructed in a descriptive manner by combining the information received from the examination of the observed lessons, the database content as well as the teachers' short pre-lesson and post-lesson interviews.

Second, the teachers' pedagogical practices were assessed through a detailed thematic analysis (Brown \& Clarke, 2006) of the videotaped lesson observations. All the videotapes were examined, and sections including the teacher's speech action focusing on a specific activity, each revealing a separate pedagogical design solution or scaffolding intervention, were selected as the units of analysis. For instance, a section might have consisted of a period where the teacher explained the next task to the class, gave guidance or feedback to a group of pupils, or demonstrated the usage of tools. The teachers' general disciplinary statements or off-task discussions with pupils were not included in the analysis. Also the periods where the pupils worked without teachers' contribution were left out of the analysis. The periods were the teacher intervened in the activity (of an individual pupil, groups or the whole class) were considered situations where the teacher actively built the pedagogical infrastructure of the setting. The duration of the selected sections varied from a few seconds (e.g., including only one guiding sentence about generating research questions) to several minutes (e.g., when a teacher supervised a group through the procedure of copying text from a file to a website). The duration was not essential for the analysis but the frequency of interventions focusing on the separate elements of the pedagogical infrastructure.

The selected sections were, first, categorized according to the main components of the Pedagogical Infrastructure Framework (technical, social, epistemological, cognitive), according to the content and focus of the teachers' intervention. The categorization was not exclusive: the same section might have been included in multiple categories because the components were often intertwined in the same section. For example, if a section included a period where the teacher guided a group of pupils to evaluate their group's collaborative working practices, it was encoded to represent both social and cognitive support.

Second, a sub-categorization was developed in a data-driven manner for assessing the quality and nature of practices that the teachers fostered through their interventions. The content analyses of videotapes were conducted using the Atlas.ti software version 7.1.5. The sub-categories were developed using an abductive strategy: continuous dialogue between the data and theoretical presumptions. The following sub-categories were used to categorize the pedagogical practices and guidance from the classroom videos:

- Technical aspects were categorized applying the levels of digital competence developed in Ilomäki, Paavola, Lakkala and Kantosalo (2014): Technical skills, Meaningful use, Broader understanding, and Participation in digital culture.

- Social aspects were categorized in the following sub-categories based on the data: Organizing groups, Equal participation, Collaboration practices, Peer commenting, External contacts, and Whole-class brainstorming. 
- Epistemic aspects were the most difficult to categorize because the practices in the cases were epistemologically so different in nature (inquiry and journal writing). The following categories were defined based on the data: Straightforward guidelines, Focus on factual knowledge, Teacher giving ideas, Defining epistemic criteria, Focus on explanatory knowledge, Conceptual examination, Using information sources, Promoting knowledge creation, and Examining the final products.

- Cognitive aspects were encoded in the following categories representing the nature of guidance and metacognitive tasks during observed lessons: Feedback from teacher, Guiding working strategies, Process-progression, Reflection, and Modelling good practices.

The final interviews of the two less-experienced teachers were transcribed verbatim and then reviewed in order to investigate how beneficial the teachers found the practice transfer process in terms of advancing their professional competence in using ICT and new types of pedagogical methods. Descriptive summaries of the answers in both case studies were constructed in relation to the following themes:

- Self-evaluation of the usefulness of tutoring and the whole practice transfer process;

- Self-evaluation of the less-experienced teachers' classroom implementation;

- Self-evaluation of the less-experienced teachers' improved competency.

\section{Results}

\subsection{The teachers' classroom implementations}

The comparison between the pedagogical practices of the more- and less-experienced teachers in both case studies is made by comparing (a) the general nature, phasing, and structuring of the pedagogical units, and (b) the frequency and nature of the pedagogical infrastructure elements in the classroom activities.

\subsubsection{Overall design of the pedagogical units in Case 1}

In Case 1, the pedagogical unit organized by MET1 closely followed the model of Progressive Inquiry (Hakkarainen 2003), which is a pedagogical model that structures learners' collaborative inquiry activities through iterative phases of formulating questions and explanations, evaluating shared efforts, and searching for information from various sources to improve the explanations created. Pupils studied wild courtyard plants and practiced the construction of a simple experimental design related to growth factors. The inquiry process had various phases where the pupils took turns in working alone (when producing research questions and commenting on others' questions and explanations), in pairs (when searching for information from literary sources), and in teams of four (when examining the courtyard plants, writing explanations on their observations and presenting the outcomes).

LET1 implemented a unit where pupils examined signs of spring in the school's surroundings. There were many similar elements in the scenario of LET1 with the scenario of MET1: the pupils' questions related to phenomena in nature, observations in the school courtyard, group work, guidance of the process through written guidelines, and web discussions about the observations. The scenario of LET1 was, however, not designed according to the Progressive Inquiry model. In an interview, LET1 explained that she did not want to follow that model directly or allocate time to teaching the working model itself to the pupils; she wanted to carry out a lighter project. Table 1 describes the main phases in the pupils' inquiry process in both units. 
Table 1

Main phases of the process in the pedagogical units of Case 1.

\begin{tabular}{ll}
\hline \multicolumn{1}{c}{ Growth factors (MET1) } & Life around the school (LET1) \\
\hline (1) Creating the context & (1) Creating the context and forming \\
(2) Creating questions and forming & groups \\
groups & (2) Taking photos \\
(3) Formulating one's own & (3) Questions to pupils in other groups \\
explanations & (4) Uploading and naming photos \\
(4) Making observations & (5) Asking questions and answering \\
(5) Interpreting observations & them \\
(6) Adding explanations from & (6) Improving the answers \\
information sources & \\
(7) Giving presentations &
\end{tabular}

\subsubsection{Overall design of the pedagogical units in Case 2}

In Case 2, the pedagogical unit of MET2 was organized as a publishing process with clear subtasks simulating the professional practices of creating texts and photographs for a digital journal. The pupils were given the responsibility for creating stories in pairs or groups that decided the themes, wrote the stories, took digital photographs, and made proposals for the layout. The stories were, e.g., about the autumn fashion, making crepes, and describing the peer-reconciliation process used in the school for solving disagreements between pupils. Pupil groups commented on each other's drafts and together evaluated all the stories and the working process at the end of the unit. The teacher modelled the process by drawing a picture of its phases on the blackboard and compared the working process with the professional editorial practices. All the pupil groups conducted the tasks in the same order, but at their own pace: one group might still have been writing their story while another group was already taking photos. The teacher guided the groups separately and in a tailored way when they reached a new phase in their process.

In the unit implemented by LET2, the general idea was that the pupils become familiar with the practice of creating stories in the school's web journal. First the pupils examined existing stories in the journal and received guidance about the writing and publishing process from MET1 and his pupils. Then pupils started writing short stories in pairs or groups of three (jokes, descriptions of pets, evaluations of computer games, etc.). The first versions were written with a word-processing program and the finished stories were copied to Magazine Factory. All the pupils were also taught to take digital photos and make a photo reportage. Some pupils were given the task of making a photo reportage of the class's "night school" activity. The pupils published varying number of stories in the journal during the process. Table 2 describes the main phases in the pupils' publishing process in both units. 
Table 2

Main phases of the process in the pedagogical unit of Case 2.

$$
\text { Web journal (MET2) }
$$

(1) Examining existing journals and forming groups

(2) Brainstorming of article topics

(3) Writing and evaluating article drafts

(4) Taking photos for the articles

(5) Publishing the articles

(6) Self-evaluation of the process and outcomes
Web journal (LET2)

(1) Demonstrating the tool and existing stories; starting article writing

(2) Demonstrating how to take photos; continuing article writing

(3) Demonstrating how to publish photos; continuing article writing

(4) An exercise about how to make a photo reportage; writing and publishing articles

(5) Reviewing, writing and publishing articles.

It may be characterized that the nature of practices in the pedagogical units of both moreexperienced teachers represented a goal-oriented, sustained process where the pupils engaged in producing one refined final product, either a research report or a journal article. In the pedagogical units of the less-experienced teachers, on the other hand, the process consisted of various sub-tasks and activities that did not form a logical continuum or were not strongly integrated with each other.

\subsection{Pedagogical infrastructure elements in the classroom activities}

The teachers' classroom practices were assessed also through a detailed analysis of the videotaped lesson observations. The number of analyzed segments in the classroom videos of each teacher was the following: MET1: 175, LET1: 153, MET2: 209, and LET2: 154.

First, all chosen segments in the videos were categorized according to the main elements of the Pedagogical Infrastructure Framework. In Figure 1 is a comparison of the frequency of categories (technical, social, epistemic and cognitive) between the classroom practices of more- and lessexperienced teachers. According to the $\chi 2$-test, there was a statistically significant difference in the distribution of frequencies, $\chi 2(3, \mathrm{~N}=833)=17.07, \mathrm{p}<0.001$.

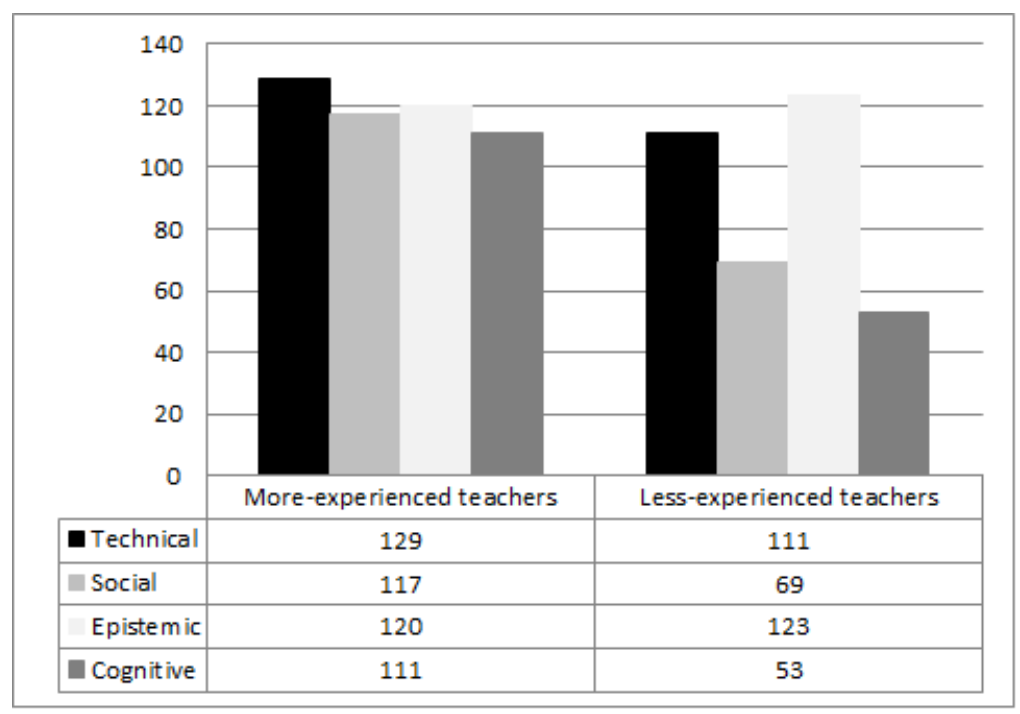

Fig. 1. Main elements of the Pedagogical Infrastructure Framework in the classroom interventions and guidance of the more- and less-experienced teachers. 
Second, all segments in the videos categorized according to the main components of the Pedagogical Infrastructure Framework were analyzed in more detail and categorized in subcategories addressing the nature of teacher intervention and guidance. Figures from 2 to 5 present the results of the analysis comparing the differences of classroom practices between more- and lessexperienced teachers.

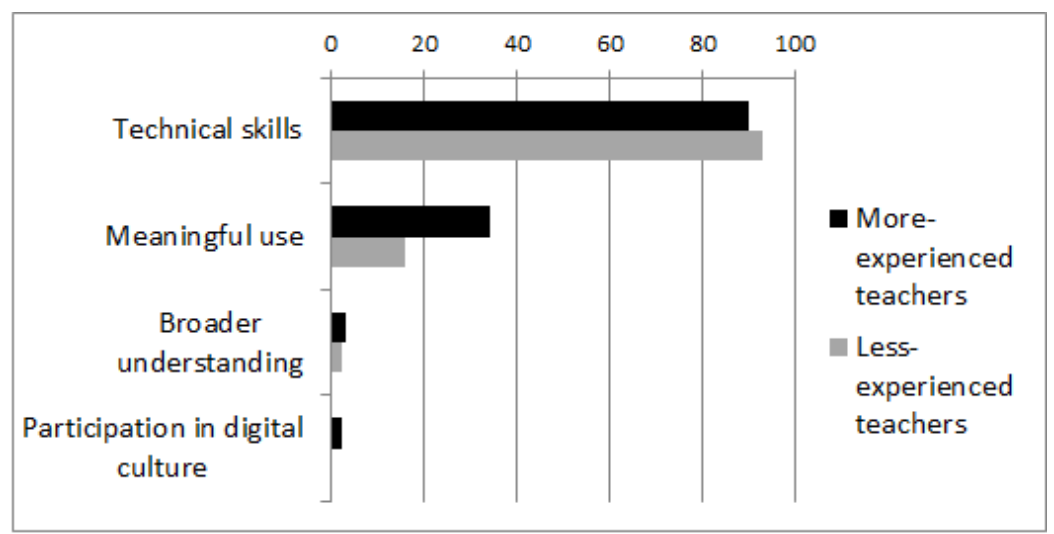

Fig. 2. The nature of the teachers' classroom interventions and guidance concerning technical aspects.

There is not much difference in the ways that teachers addressed technical issues with pupils (Figure 2). The more-experienced teachers had somewhat more guidance concerning the meaningful use of technology (e.g., recommending good tools for story writing). In all cases, the pupils used the tools for the first time; therefore the main emphasis was on learning to use them technically. The overall $\chi^{2}$ was not able to be computed because of low $(<1)$ expected frequencies.

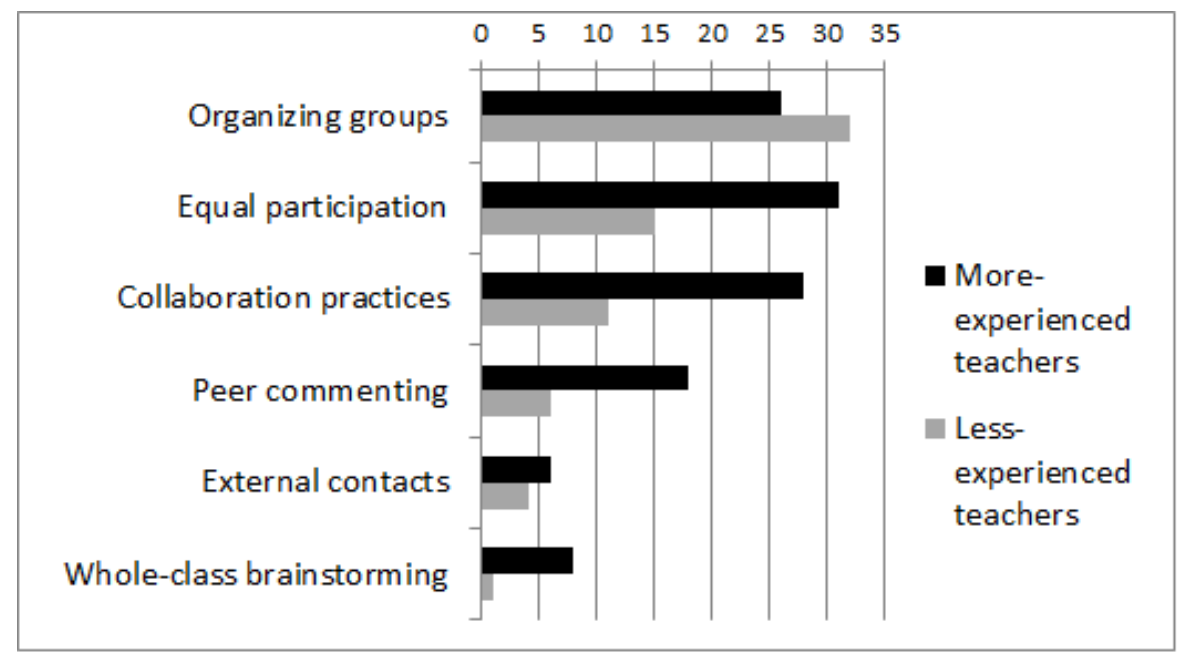

Fig. 3. The nature of the teachers' classroom interventions and guidance concerning social aspects.

The results presented in Figure 3 strengthen the view that was received from examining the overall structuring of the activities in each case: the less-experienced teachers spent more effort in organizing and re-organizing pupil groups, whereas the more-experienced teachers used more versatile and better-designed types of social activities, and they guided and directed effective group work in a more elaborate way. According to the $\chi 2$-test, there was a statistically significant difference in the distribution of frequencies, $\chi^{2}(5, \mathrm{~N}=186)=13.98, \mathrm{p}<0.05$. 


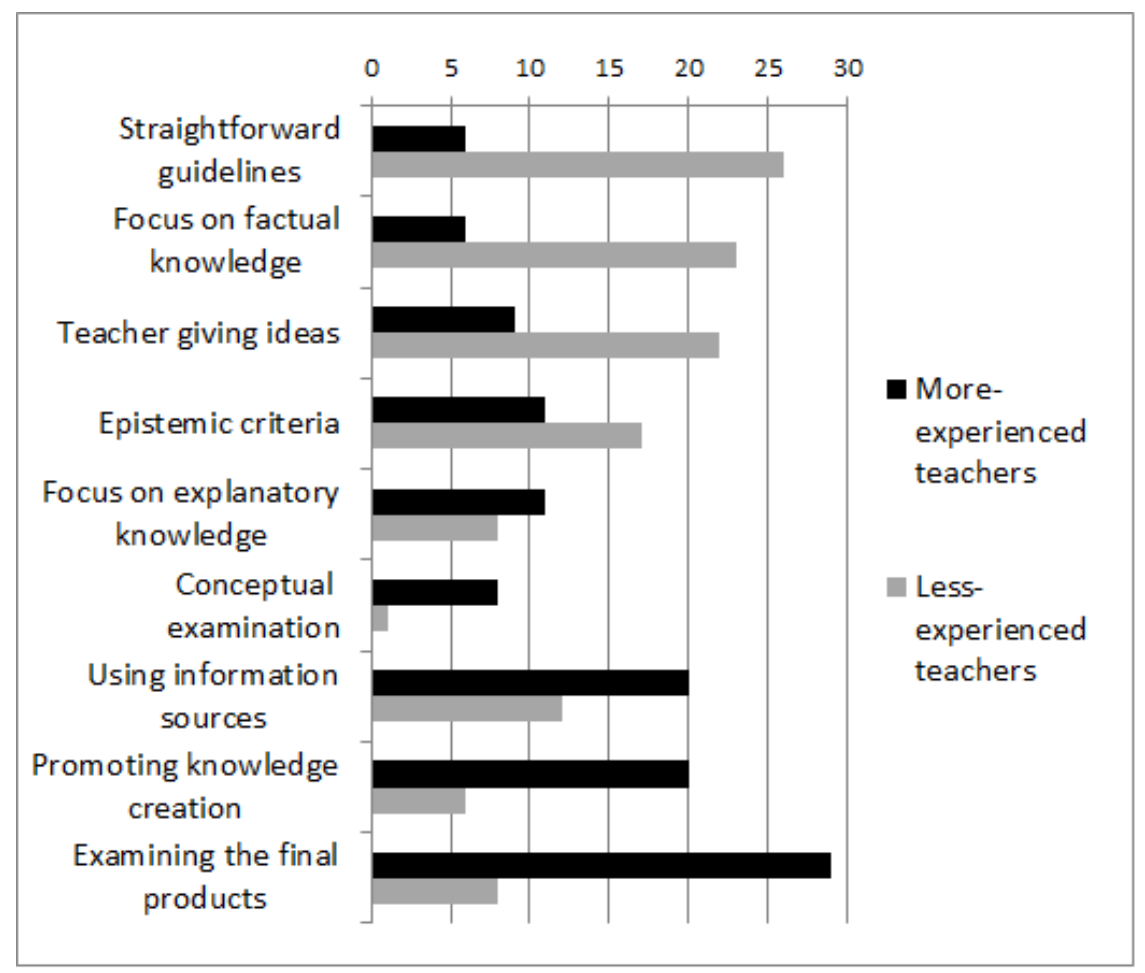

Fig. 4. The nature of the teachers' classroom interventions and guidance concerning epistemic aspects.

The teachers' way of orchestrating epistemic aspects (Figure 4) in the classroom activities was very different: the less-experience teachers focused on straightforward guidelines (e.g., directing to write a research question) and factual knowledge (e.g., identifying plants), whereas the moreexperienced teachers addressed pupils' own epistemic agency, such as knowledge creation (e.g., encouraging pupils to invent many answers) or the examination of final products (e.g., evaluating the final stories together). According to the $\chi 2$-test, there was a statistically significant difference in the distribution of frequencies, $\chi 2(8, \mathrm{~N}=243)=56.55, \mathrm{p}<0.0005$.

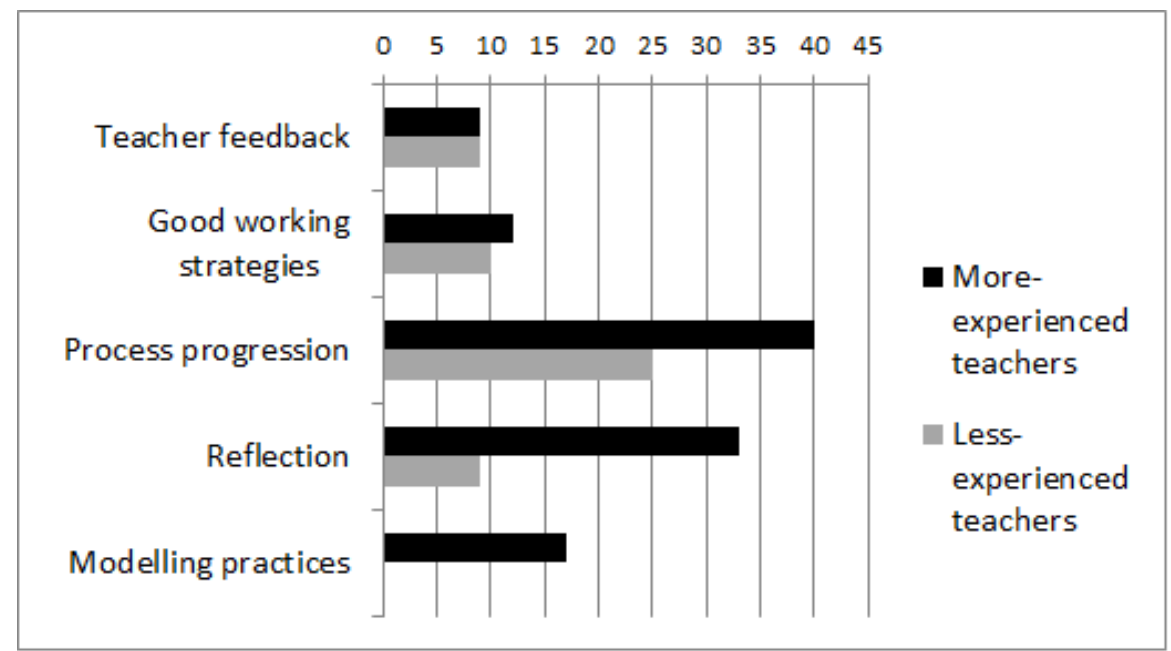

Fig. 5. The nature of the classroom interventions and guidance of the more- and less-experienced teachers concerning cognitive aspects.

Concerning the cognitive and metacognitive aspects (Figure 5), both more- and lessexperienced teachers gave as much feedback to pupils and guided good working strategies (e.g., 
how to use peer comments for improving the text). The differences in frequencies are bigger concerning more advanced metacognitive activities, such as reflection (e.g., directing pupils to selfevaluate their group work) or modelling the working process and the overall practices (e.g., depicting the phases of the process). According to the $\chi 2$-test, there was a statistically significant difference in the distribution of frequencies, $\chi^{2}(4, \mathrm{~N}=164)=15.82, \mathrm{p}<0.005$.

\subsection{Experienced benefits of the practice transfer process}

The final interviews of the two less-experienced teachers were examined to investigate how they experienced the success of the practice transfer process themselves.

In Case 1, LET1 evaluated that the training materials were of good quality, and that the videos helped to figure out the process progression in the classroom. She did not use the written scenario much because she decided not to conduct her project in a similar way, but she thought that it was quite easy for her to create her own scenario. The greatest benefit of tutoring for LET1 was that it encouraged her to try out a larger and more challenging project than she would have done otherwise. For example, she would not have dared to give digital cameras to such young pupils to take out if she had not known that MET1 had done it before. It was very important that the guidance from the more-experienced teacher was easily and directly available. About the effectiveness of the entire practice transfer process, LET1 thought that for teachers like she who are already quite competent in using ICT in general and have some experience in using digital technology in teaching, the materials and some motivation from a tutor would be sufficient for trying out new practices.

When evaluating her classroom implementation, LET1 spontaneously gave a grade of $8+$ to herself for success in implementation. She was annoyed by the reckless atmosphere in the classroom, but had observed that the pupils liked the project and the activities. She remarked that often when teachers apply new teaching methods (more open, more activating, more challenging to organize), they experience the situation as stressful, but that the pupils like them. LET1 said that it was very easy and useful to follow some concrete examples provided by MET1 for organizing the activities. She thought that without the examples from MET1, she probably would not have conducted as multifaceted and systematic a process (e.g., organizing the groups or including explicit phases of question generation and commenting in the process).

Concerning her improved competency, LET1 evaluated that her skills in using the Web-based collaboration system in multifaceted ways with the pupils improved (e.g. how to structure the virtual areas for pupils' web-discussions and group work). Also her confidence in using digital cameras with pupils increased. In general, the experience gave her self-confidence in trying out new things in teaching with digital technology. She said that probably next time she would be able to make better plans about when and how to give instructions to pupils, and would also be more able to follow pupils' activities in Web-based forums.

In Case 2, LET2 explained that the written material had helped him to figure out the idea of the example project but that the discussions with the tutor were more important: asking from somebody is easier than reading from a written description. He said that the videos were more useful than the text description because they actually showed how the activities were carried out in the classroom by MET2. LET2 thought that flexibility in tutoring was very important: it was good to be able to talk with the tutor at school when needed, plan the phases gradually according to process progression, and change plans flexibly. Concerning the entire practice transfer process, LET2 evaluated that for the tutored teacher this is a much more effective way to learn than being just one of several participants in a teacher training course.

LET2 was quite satisfied with his classroom implementation; he believed that the pupils liked it. He remarked that this was the pupils' first attempt at journal writing and using the publishing tool. He realized that the stories they had written were quite modest, but it would be very important 
to be able to continue the practice next year and produce more challenging articles. LET2 considered that MET2 explained very well how he had carried out the process, but it was quite easy for him to design his own way of organizing the journal-writing process after just seeing how the publishing tool worked. LET2 thought that it was important to have the freedom to choose one's own way in implementing the pedagogical idea.

In relation to improved competency, LET2 reported that he learnt how to use the tool for Web publishing, and he became acquainted with using laptops with pupils in versatile ways. He also learned to avoid some problematic technical issues related to the infrastructure of his school (e.g., servers). Regarding pedagogical competency, LET2 answered that it was not easy to specify any particular issue, except perhaps the usage of IVB for giving guidance and various practices related to the overall organization of teaching. In general, LET2 thought that he is now capable of initializing a similar publishing project himself.

\section{Discussion and conclusions}

\subsection{The success of practice transfer}

The practice transfer process through collaboration between colleagues in the same school turned out to be a light-weight and flexible way to provide support for in-service teachers willing to improve their competence in technology-enhanced learning. The tutored teachers succeeded well in orchestrating the classroom activities and concrete technology usage, even though they experimented with new type of pedagogues and digital tools for the first time. Both teachers were quite pleased with their classroom implementations, but they also identified shortcomings and were convinced that they are able to improve their practices in the future. Both tutored teachers mentioned that it is important to have freedom to apply the ideas and models provided by the tutor in their own way.

The teachers thought that the models and tutoring from their more experienced colleague encouraged them to try more challenging practices and use of ICT than they would have done on their own, and gave them self-confidence and abilities to revise plans if needed. As Jones and Vincent (2010) argued, peer tutors provide a safety-net back-up for tutored teachers in the first lessons when they try out new, challenging practices. Through systematic tutoring, teachers are able to take the first steps, crossing boundaries in their technological-pedagogical competence, and advance farther than they would do alone. As the study by Orlando (2014) witnessed, sometimes it might take a long time (several years) for teachers to start changing their pedagogical practices with ICT.

The tutored teachers considered that the scenario descriptions and particularly the videos were useful, but still the most important support was the collaboration with the more-experienced teacher. The most valuable feature was the flexibility and easy availability of the support. The sharing of expertise between colleagues in this way can be beneficial also for increasing collaboration and for spreading common practices in the whole teacher community of a school.

Nevertheless, some difference in the pedagogical nature of the practices between the more- and less-experienced teachers remained quite clear regardless of example materials and tutoring. A distinct characteristic in the units designed by both experienced teachers was that pupils' activities simulated meaningful professional practices, either scientific inquiry or journal publishing. The classroom designs were sustained, goal-oriented working processes consisting of well-organized activities where the various elements of the pedagogical infrastructure were smoothly integrated. Successive phases of the process were logically built on the previous ones. The usage of technology served the overall goal and the activities provided pupils with a possibility to practice advanced technical and academic skills in a relevant context; such approach is considered supporting pupils' wider digital competence (Erstad, 2010; Ilomäki et al., 2014; Tierney, Bond, \& Bresler, 2006). The 
overall designs of the pedagogical units by the less-experienced teachers were not as coherent; the multiple activities only loosely related to the main goal and to each other. The activities designed by the less-experienced teachers can be characterized as a collection of activities related to a certain theme instead of creating a logical continuum with clear process organization. Corresponding results of the differences between the practices of less and more competent teachers have been reported also in previous studies (Ilomäki, Lakkala, \& Paavola, 2006; Puntambekar et al., 2007).

Based on the analysis of the scaffolding practices in the classroom, the pedagogical approach of the less-experienced teachers remained somewhat conventional. The teachers concentrated on factual knowledge, gave mainly straightforward guidelines for epistemic activities, and took a central role in idea generation. They mostly guided practical issues in technology use and group organization, whereas the coordination of collaborative activities in groups and the promotion of pupils' metacognitive activities and competence was less sophisticated than those of the moreexperienced teachers. The transfer process supported the change in surface-level activities but the deep-level pedagogical change did not actualize. For a teacher, novice in using digital technology, the classroom management with the new tools is a primary challenge and often the most concerned issue at the start of the change process. Teachers want to feel confident with what they are doing, and changing their practices simultaneously in several levels is often too demanding.

\subsection{Recommendations for improving tutoring and the practice transfer method}

Based on the results of the study, some recommendations can be made about how to improve the tutoring and the practice transfer process. Pedagogical beliefs affect how teachers integrate technology in their teaching (Voogt et al., 2013). The tutors should strongly direct the discussions towards educational improvement by making the deeper pedagogical ideologies, reasons, and solutions in the scenarios explicit and exposed to critical evaluation and cultivation. For instance, in the investigated cases the tutors could have emphasized the relevancy of sustained, goal-oriented activity where the authentic nature of the task and pupils' own ideas and questions direct the process, not the teacher's ideas or unconnected exercises.

In the cases of the present study, there was a clear difference between the more- and lessexperienced teachers in the focus of guidance and scaffolding actions in the classroom. It might be difficult for experienced teachers to explicate, or even realize, their guidance practices in the classroom, because such competence is at the core of teacher's expertise and often based on tacit knowing (Toom, 2008). Perhaps the Pedagogical Infrastructure Framework or a similar conceptualization could help in directing the collegial discussions towards better promoting the pedagogical awareness of less-experienced teachers. Even though the practice transfer model used in the present study is meant for a light-weight, easily applied method in the everyday practice of any school, some training or explicit pedagogical guidelines for the tutoring teachers might help them avoid focusing only on surface level phenomena, such as the digital tools, which could increase the effectiveness of the practice transfer process.

\section{Acknowledgements}

This work was partially supported by the Lifelong Learning Programme of the European Union under Grant 141929-2008-LLP-FR-COMENIUS-CMP (the FICTUP project). We want to thank all teachers and students who participated in the investigated pedagogical units and all the partners participating in the FICTUP project. 


\section{References}

Bakkenes, I., Vermunt, J., \& Wubbels, T. (2010). Teacher learning in the context of educational innovation: Learning activities and learning outcomes of experienced teachers. Learning and Instruction, 20, 533-548.

Bielaczyc, K. (2006). Designing social infrastructure: Critical issues in creating learning environments with technology. Journal of the Learning Sciences, 15, 301-329.

Braun, V., \& Clarke, V. (2006). Using thematic analysis in psychology. Qualitative Research in Psychology, 3, 77-101.

Condie, R., Munro, B., Seagraves, L., \& Kenesson, S. (2007). The impact of ICT in schools - a landscape review. Coventry: British Educational Communications and Technology Agency.

Erstad, O. (2010). Educating the digital generation. Nordic Journal of Digital Literacy, 1, 56-70.

European Commission (2013). Survey of schools: ICT in education. Luxembourg: Publications Office of the European Union.

Feilzer, M. Y. (2009). Doing mixed methods research pragmatically: Implications for the rediscovery of pragmatism as a research paradigm. Journal of Mixed Methods Research, 4, 616.

FICTUP (2010). Guidelines for the FICTUP tutoring model - How to promote ICT use in class. Retrieved from: http://www.fictupproject.eu/index.php/Guidelines_for_the_FICTUP_tutoring_model

FICTUP (2013a). Exploring growth factors. Applying inquiry learning and virtual forums. Retrieved from: http://www.fictupproject.eu/index.php/Exploring_growth_factors._Applying_inquiry_learning_and_virtual_foru ms

FICTUP (2013b). School children's web journal. Publishing with Magazine Factory tool. Retrieved from: http://www.fictupproject.eu/index.php/School_children\%E2\%80\%99s_Web_journal._Publishing_with_Magazin e_Factory_tool.

Fogarty, R., \& Pete, B. (2010). Professional learning 101: A syllabus of seven protocols. Phi Delta Kappan, 91(4), 32-34.

Hakkarainen, K. (2003). Progressive inquiry in a computer-supported biology class. Journal of Research in Science Teaching, 40(10), 1072-1088.

Hyo-Jeong S., \& Kim, B. (2009). Learning about problem based learning: Student teachers integrating technology, pedagogy and content knowledge. Australasian Journal of Educational Technology, 25(1), 101-116.

Ilomäki, L. (2008). The Effects of ICT on School: Teachers' and Students' Perspectives. Univeristy of Turku Series B, Humaniora, 314.

Ilomäki, L., Lakkala, M., \& Paavola, S. (2006). Case studies of learning objects used in school settings. Learning, Media, and Technology, 31(3), 249-267.

Ilomäki, L., Paavola, S., Lakkala, M., \& Kantosalo, A. (in press). Digital competence - an emergent boundary concept for policy and research. Education and Information Technologies. doi:10.1007/s 10639-014-9346-4.

Jimoyiannis, A., \& Komis, V. (2007). Examining teachers' beliefs about ICT in education: Implications of a teacher preparation programme, Teacher Development 11(2), 149-173.

Jones C., Dirckinck-Holmfeld, L., \& Lindström, B. (2006). A relational, indirect, meso-level approach to CSCL design in the next decade. International Journal of Computer-Supported Collaborative Learning 1, 35-56.

Jones, A., \& Vincent, J. (2010). Collegial mentoring for effective whole school professional development in the use of IWB technologies. Australasian Journal of Educational Technology, 26(4), 477-493. 
Karagiorgi, Y., \& Charalambous, K. (2006). ICT in-service training and school practices: in search for the impact. Journal of Education for Teaching, 32, 395-411.

Krumsvik, R. (2008). Situated learning and teachers' digital competence. Education \& Information Technologies, 13, 279-290.

Lakkala, M., L. Ilomäki, L., \& Kosonen, K. (2010). From instructional design to setting up pedagogical infrastructures: Designing technology-enhanced knowledge creation. In B. Ertl (Ed.), Technologies and practices for constructing knowledge in online environments: Advancements in learning (pp. 169-185). New York: Information Science Reference.

Lakkala, M., Muukkonen, H., \& Hakkarainen, K. (2005). Patterns of scaffolding in computermediated collaborative inquiry. Mentoring \& Tutoring: Partnerships in Learning, 13(2), 281300.

OECD (2010a). Are the new millennium learners making the grade? Technology use and educational performance in PISA 2006. Paris: OECD Publishing.

OECD. 2010b. Inspired by technology, driven by pedagogy. A systemic approach to technologybased school innovations. Educational Research and Innovation. Paris: OECD Publishing.

OECD (2011). PISA 2009 Results: Students online: digital technologies and performance (Vol. VI). Paris: OECD Publishing.

Orlando, J. (2009). Understanding changes in teachers' ICT practices: a longitudinal perspective. Technology, Pedagogy and Education, 18 (1), 33-44.

Orlando, J. (2014). Teachers' changing practices with information and communication technologies: An up-close, longitudinal analysis. Research in Learning Technology, 22, 21354. doi:10.3402/rlt.v22.21354

Paavola, S., Lipponen, L., \& Hakkarainen, K. (2002). Epistemological foundations for CSCL: A comparison of three models of innovative knowledge communities. In G. Stahl (Ed.), Computer support for collaborative learning: Foundations for a CSCL community (pp. 24-32). Hillsdale: Erlbaum.

Puntambekar, S., Stylianou, A., \& Goldstein, J. (2007). Comparing classroom enactments of an inquiry curriculum: Lessons learned from two teachers. The Journal of the Learning Sciences, $16,81-130$.

Putnam, R., \& Borko, H. (2000). What do new views of knowledge and thinking have to say about research on teacher learning? Educational Researcher, 29, 4-15.

Scardamalia, M., \& Bereiter, C. (2006). Does education for the knowledge age need a new science? European Journal of School Psychology, 3, 21-40.

Starkey, L. (2010). Supporting the digitally able beginning teacher. Teaching and Teacher Education, 26, 1429-1438.

Tierney, R. J., Bond, E., \& Bresler, J. (2006). Examining literate lives as students engage with multiple literacies. Theory Into Practice, 45(4), 359-367.

Toom, A. (2008). Tacit pedagogical knowing: At the core of teacher's professionality. Saarbrucken: VDM Verlag Dr. Muller.

Voogt, J., Fisser, P., Pareja Roblin, N., Tondeur, J., \& van Braak, J. (2013). Technological pedagogical content knowledge - a review of the literature. Journal of Computer-Assisted Learning, 29, 109-121.

Wang, Y. (2006). Stand-alone computer courses in teachers' IT training. EDUCAUSE Quarterly, 29(3), 8-10.

Zhou, G. (2007). Adoption of educational technology ten years after setting strategic goals: A Canadian university case. Australian Journal of Educational Technology, 23(4), 508-528. 